
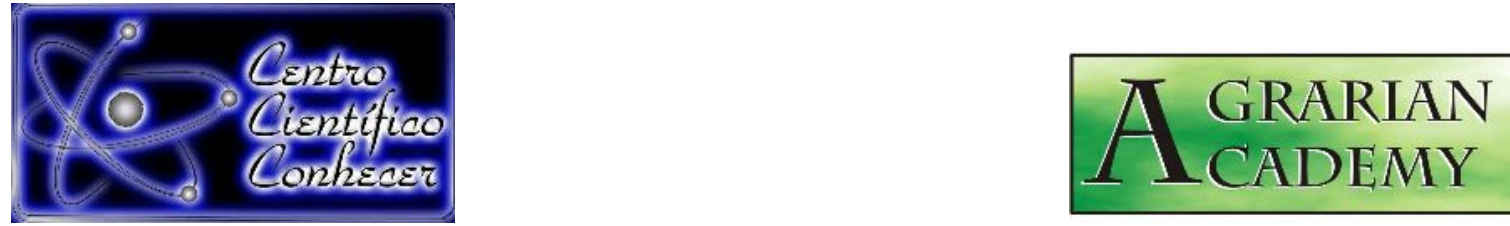

\title{
EFEITO ALELOPÁTICO DE CENTEIO NA GERMINAÇÃO E CRESCIMENTO DE PLÂNTULAS DE BETERRABA
}

\footnotetext{
Viviane Aparecida Martinelli ${ }^{1}$; Vanessa Neumann Silva ${ }^{2}$

${ }^{1}$ Acadêmica do curso de Agronomia, Universidade Federal da Fronteira Sul, campus ChapecóSC, Brasil. E-mail: vivi.wandinho@gmail.com.

${ }^{2}$ Profa Adjunta, Doutora em Fitotecnia, Universidade Federal da Fronteira Sul, campus Chapecó-SC, Brasil.
}

Recebido em: 14/07/2018 - Aprovado em: 28/07/2018 - Publicado em: 31/07/2018

DOI: 10.18677/Agrarian_Academy_2018a20

\begin{abstract}
A alelopatia pode inibir ou estimular o desenvolvimento de plantas. O uso de plantas para cobertura do solo pode resultar em efeitos alelopáticos na germinação e desenvolvimento de plântulas através da liberação de metabólitos secundários (aleloquímicos). Assim, o presente trabalho teve por objetivo verificar se o extrato de centeio exerce ação alelopática na germinação e crescimento de plântulas de beterraba. $O$ delineamento experimental utilizado foi inteiramente casualizado, em esquema fatorial $2 \times 4$ (cultivares $\times$ concentrações), com cinco repetições. Foram utilizadas sementes de beterraba, das cultivares Early Wonder e Vermelha Comprida. Os extratos foram preparados utilizando-se plantas inteiras de centeio crioulo, nas concentrações de 0 (testemunha), 25, 50 e 100\%. As sementes foram acondicionadas em caixas plásticas do tipo gerbox, com papel germitest umedecido com os extratos. As variáveis analisadas foram: porcentagem de germinação, de sementes não germinadas e plântulas anormais, índice de velocidade de geminação, comprimento de parte aérea e de raízes de plântulas, e massa seca da parte aérea e de raízes das plântulas. Os dados obtidos foram submetidos à análise de variância e quando esta foi significativa procedeu-se à análise de regressão. $O$ extrato de centeio interferiu de forma negativa na germinação de sementes de beterraba. O crescimento de plântulas de beterraba é afetado pelo extrato de centeio, com efeito variável em função da cultivar.
\end{abstract}

RESUMO

PALAVRAS CHAVE: Alelopatia. Beta vulgaris. Secale cereale.

\section{ALELOPATIC EFFECT OF RYE ON THE GERMINATION AND GROWTH OF BEET SEEDS}

\begin{abstract}
Allelopathy may inhibit or stimulate plant development. The use of plants to cover the soil can result in allopathic effects on the germination and early seedlings development of through the release of secondary (alelochemical) metabolites. Thus, the present work aims to verify if rye extract exerts allelopathic action on germination and seedlings growth of beet. The experimental design was completely randomized, in a $2 \times 4$ factorial scheme (cultivars $x$ concentrations), with five replications. Beet seeds, Early Wonder and Vermelha Comprida cultivars were used. The extracts were AGRARIAN ACADEMY, Centro Científico Conhecer - Goiânia, v.5, n.9; p.195 2018
\end{abstract}


prepared using whole rye plants, in concentrations of 0 (control), 25, 50 and $100 \%$. The seeds were conditioned in gerbox plastic boxes, with germitest paper moistened with the extracts. The analyzed variables were: percentage of germination, of nongerminated seeds and abnormal seedlings, speed germination index, length of shoot and roots of seedlings, and seedling dry mass (shoot and roots). The data were submitted to analysis of variance and when this was significant, the regression analysis was performed. The rye extract reduces beet seed germination. Beet seedlings growth is affected by rye extract, with variable effect as a function of the cultivar.

KEYWORDS: Allelopathy. Beta vulgaris. Secale cereale.

\section{INTRODUÇÃO}

A alelopatia é um fenômeno biológico comum pelo qual um organismo produz compostos bioquímicos que influenciam o crescimento, sobrevivência, desenvolvimento e reprodução de outros organismos; estes compostos são conhecidos como aleloquímicos e têm efeitos benéficos ou prejudiciais nos organismos alvos (CHENG ; CHENG, 2015). Os aleloquímicos podem estimular ou inibir a germinação e o crescimento das plantas, e permitir o desenvolvimento de culturas com baixo teor de resíduos fitotóxicos na água e no solo, facilitando assim o tratamento de águas residuais e a reciclagem (CHENG; CHENG, 2015). Vários mecanismos têm sido estudados sobre a liberação de aleloquímicos, incluindo volatilização ou lixiviação de partes aéreas, exsudação de raízes e decomposição de resíduos de plantas no solo (LATIF et al. 2017).

A utilização de plantas de cobertura em sistemas de rotação na agricultura pode trazer muitos benefícios. Segundo Blanco-Canqui et al. (2015) culturas de cobertura têm o potencial de contribuir para a melhoria das propriedades e processos do solo, que, por sua vez, afetam os serviços ecossistêmicos do solo e a multifuncionalidade dos agroecossistemas. Em cultivos de hortaliças vem se utilizando o Sistema de Plantio Direto (SDPH). Um dos preceitos desse sistema é o uso de cobertura do solo. Larney et al. (2016) avaliando a resposta de beterraba açucareira, em um sistema de rotação de culturas, com uso de plantas de cobertura e manejo conservacionista do solo, durante 12 anos, verificaram maior produtividade e maior extração de açúcar, comparado ao sistema convencional.

A cobertura do solo também pode ser estratégica para redução da população de plantas espontâneas nos cultivos. Segundo Guerra et al. (2016) a redução de produtividade em beterraba, pela competição, está relacionada ao porte da cultura, que favorece o crescimento das plantas daninhas; somado a isso, devido ao espaçamento estreito entre as linhas de cultivo, a capina pode danificar as raízes e comprometer a qualidade e a produtividade.

Desta forma, o uso de plantas de cobertura, para supressão de plantas espontâneas, pode se tornar uma ferramenta valiosa para o cultivo de beterraba. $\mathrm{O}$ centeio é uma espécie com grande potencial para uso em cobertura de solo. Vilanova et al. (2014), avaliando a interferência de plantas de cobertura sobre a incidência de plantas invasoras e a produção de cebola sob sistema de plantio direto, verificaram menor produção de matéria seca de plantas invasoras, com uso de centeio associado a nabo forrageiro para cobertura do solo. Além disso, plantas de centeio promovem maior agregação de solo e estruturação (MOORE et al. 2014) e retenção de água (BASCHE et al. 2016). Ziech et al. (2015) constataram que plantas de centeio possuem taxa de decomposição de palhada intermediária, 
comparada as outras plantas muito utilizadas para cobertura, como aveia preta e ervilhaca, por exemplo, e mantém em superfície do solo, quantidades entre 28 a $37 \%$ da matéria seca após 122 dias, em condições climáticas da região Sul do Brasil.

O centeio concorre bem com plantas espontâneas, pois possui a capacidade de produzir componentes alelopáticos; vários compostos químicos alelopáticos já foram identificados em centeio, incluindo as benzoxazinonas, ácidos hidroxâmicos, como DIBOA (2,4-di-hidroxi-2H-1,4-benzoxazin-3(4H)-ona) e seus metabólitos (NIEMEYER, 2009). Estas substâncias podem também afetar culturas de interesse econômico, como por exemplo, a cultura da alface. Venturelli et al. (2015) constataram que aleloquímicos derivados de DIBOA reduzem o crescimento de plântulas de alface e Arabidopsis thaliana, atuando na cromatina, a nível celular, inibindo a desacetilação de histonas, tanto in vitro quanto in vivo. Contudo, não há informações na literatura sobre os possíveis efeitos residuais de plantas de centeio no cultivo de beterraba. Assim, o presente trabalho teve por objetivo verificar se 0 extrato de centeio exerce ação alelopática na germinação e crescimento de plântulas de beterraba.

\section{MATERIAL E MÉTODOS}

A pesquisa foi desenvolvida no Laboratório de Sementes da Universidade Federal da Fronteira Sul, campus Chapecó - SC. Foi utilizado o delineamento inteiramente casualizado (DIC), com esquema fatorial $2 \times 4$ (cultivares $x$ doses), com cinco repetições.

Para a elaboração dos extratos, foram utilizadas plantas inteiras de centeio crioulo, colhidas na fase reprodutiva. As amostras foram obtidas da área experimental da Universidade Federal da Fronteira Sul, campus Chapecó-SC; após a coleta, as plantas foram lavadas, secadas e armazenadas em sacos plásticos e congeladas até o momento da utilização das mesmas. Para o preparo do extrato utilizou-se a metodologia proposta por Mohammadi et al. (2016); para tanto, foram utilizadas 100 gramas das plantas, as quais foram trituradas com $1000 \mathrm{~mL}$ de água destilada, em liquidificador, adicionando-se a água destilada logo após, e deixando em repouso por 24 horas; logo após foi realizada a filtragem e então utilizados no experimento. Os tratamentos consistiram de cultivares: Vermelha comprida e Early Wonder, em combinação com as doses de: 0 (testemunha), 25, 50 e 100\% de concentração do extrato de centeio.

Para avaliar o efeito dos tratamentos foram utilizados os seguintes testes:

Germinação: realizado com metodologia adaptada das Regras para Análise de Sementes (BRASIL, 2009). As sementes foram acondicionadas em caixas plásticas do tipo gerbox, com papel Germitest. Foram utilizadas cinco repetições de 25 sementes. Em cada gerbox foram colocadas duas folhas de papel, umedecidas com os extratos, na proporção de 2,5 vezes o peso do papel seco. $\mathrm{Na}$ sequência, os gerbox foram colocados em câmeras de germinação do tipo BOD (Biochemical Oxygen Demand) com temperatura de $20^{\circ} \mathrm{C}$ e fotoperíodo de 12 horas. As sementes permaneceram por 14 dias na BOD, sendo acompanhadas diariamente. As avaliações do teste de germinação foram realizadas aos quatro e 14 dias após a semeadura (DAS), conforme os critérios estabelecidos nas Regras para Análise de Sementes (BRASIL, 2009).

Velocidade de Germinação: diariamente foi realizada a contagem de sementes germinadas, calculando-se a velocidade de acordo com a fórmula proposta por Maguire (1962).

AGRARIAN ACADEMY, Centro Científico Conhecer - Goiânia, v.5, n.9; p. 1972018 
Crescimento de plântulas: realizada com metodologia adaptada de ISTA (2013); aos 14 DAS, foram retiradas aleatoriamente, de cada repetição, 20 plântulas, as quais foram mensuradas com régua graduada, separando-se a raiz e a parte aérea, expressando-se os resultados em $\mathrm{cm}$.

Massa seca de plântulas: as mesmas plantas utilizadas para avaliar o comprimento foram separadas em raiz e parte aérea e submetidas a secagem em estufa de circulação de ar forçado, regulada a $65^{\circ} \mathrm{C}$, até que obtiveram peso constante, sendo posteriormente pesadas em balança de precisão de 0,0001 g (ISTA, 2013). Os dados obtidos foram submetidos a análise de variância e quando esta foi significativa procedeu-se à análise de regressão.

\section{RESULTADOS E DISCUSSÃO}

Os valores médios obtidos para a germinação de sementes de beterraba diferiram entre as doses e cultivares (Figura 1A), sendo que conforme as doses aumentaram, o percentual de germinação diminuiu, e a cultivar que apresentou menor desempenho foi a Vermelha Comprida. De forma semelhante a esses resultados, Castagnara et al. (2012), verificaram que o extrato de aveia (Avena sativa), reduziu a germinação de sementes de pepino. Em relação aos valores médios de sementes não germinadas de beterraba (Figura 1B) nota-se que houve diferença entre as cultivares, com pior desempenho da cultivar Vermelha Comprida.
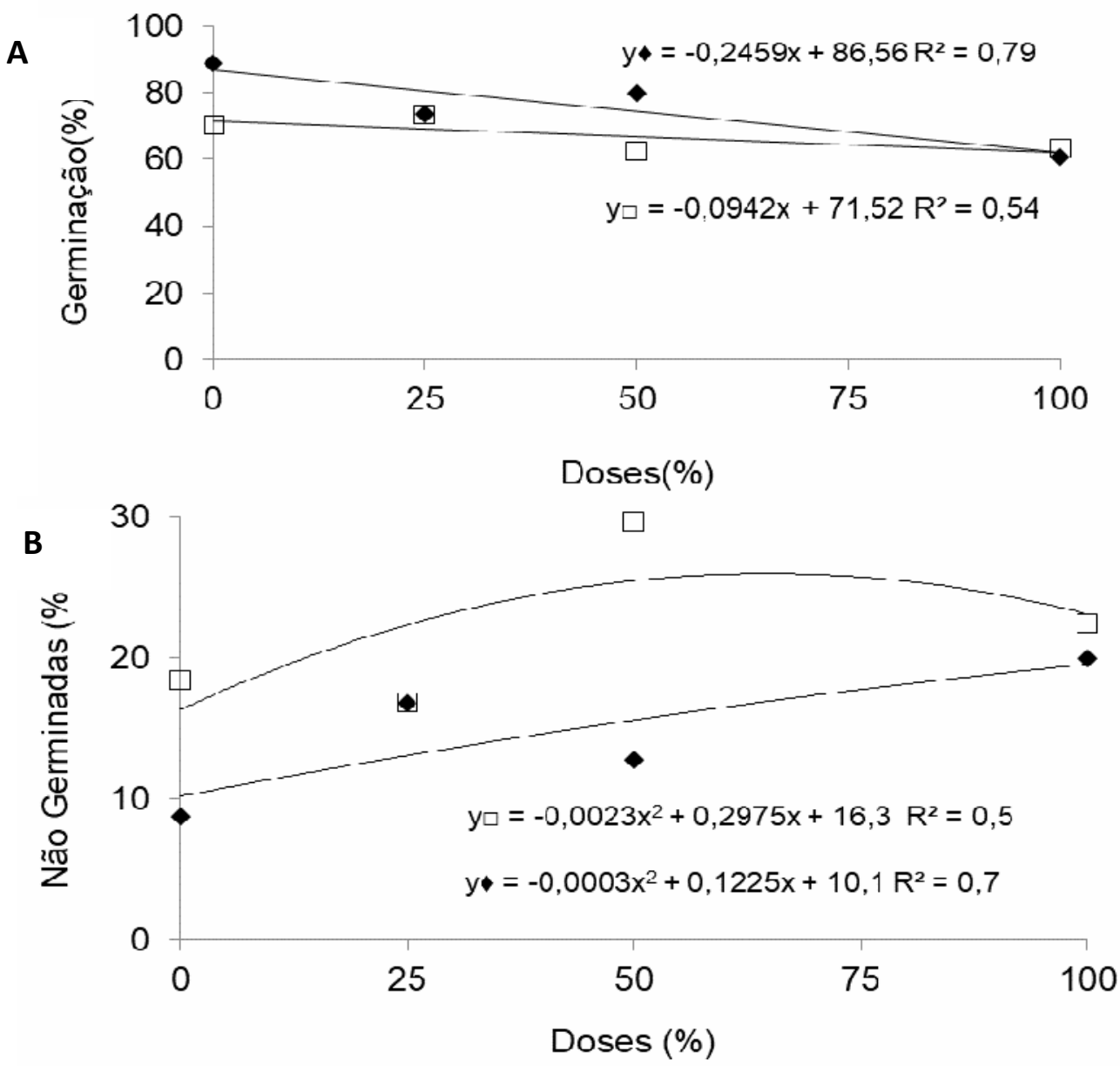

FIGURA 1. Valores médios de germinação $(A)$ e de sementes não germinadas $(B)$ de beterraba, cultivares Vermelha Comprida (\$) e Early Wonder ( ), sob efeito de diferentes doses do extrato de centeio. 
Os valores médios de plântulas anormais são apresentados na tabela 1; é possível observar que a cultivar Early Wonder teve uma maior quantidade de plântulas anormais, sendo que os tratamentos influenciaram negativamente as sementes, aumentando os valores de plântulas com anormalidades, embora não tenha sido possível ajustar um modelo de equação de regressão para os dados. Grande parte das plântulas apresentou deformação da parte aérea e raízes.

TABELA 1. Valores médios de plântulas anormais (AN) de beterraba, cultivares Vermelha Comprida e Early Wonder, sob efeito de diferentes doses do extrato de centeio.

\begin{tabular}{ccccccc}
\hline \multirow{2}{*}{ Cultivares } & \multicolumn{7}{c}{ AN (\%) } \\
\cline { 2 - 7 } & $\mathbf{0}$ & $\mathbf{2 5}$ & $\mathbf{5 0}$ & $\mathbf{1 0 0}$ & Médias & CV (\%) \\
\hline Early Wonder & 2,40 & 10,40 & 7,20 & 19,20 & 9,80 & \multirow{2}{*}{56,00} \\
Vermelha Comprida & 11,20 & 10,40 & 8,00 & 14,40 & 11,00 & \\
\hline
\end{tabular}

Carvalho et al. (2014) verificaram que sementes de alface tratadas com extratos aquosos de gramíneas, sendo: sorgo, milheto e aveia preta (separadamente), obtiveram redução de plântulas normais de até $56 \%$, sendo o extrato de milheto o mais prejudicial a espécie, seguido do sorgo e aveia preta.

O sistema radicular das plantas é sensível à ação de aleloquímicos, isto porque 0 alongamento depende de divisões celulares, que quando inibidas, comprometem o desenvolvimento normal; plantas de centeio produzem quantidades significativas de ácidos hidroxâmicos e compostos fenólicos, que quando isolados das plantas e testados em bioensaios, se mostram tóxicos para outras plantas (ASLAM et al., 2017); ainda, segundo esses autores, pela ação desses compostos fenólicos, ocorrem alterações nas membranas celulares, as quais passam a não ter permeabilidade seletiva específica, causando distúrbios no fluxo de íons e condutividade hidráulica em raízes de plantas. Sendo assim é possível que os compostos aleloquímicos de centeio prejudicaram o desenvolvimento de plântulas normais de beterraba, já que houve má formação nas raízes e necrose nas mesmas.

A variável índice de velocidade de germinação (IVG), apresentada na tabela 2, não diferiu estatisticamente, entre doses e cultivares.

TABELA 2. Valores médios de índice de velocidade de germinação (IVG) de sementes de beterraba, cultivares Early Wonder e Vermelha Comprida, sob efeito de diferentes doses do extrato de centeio.

\begin{tabular}{ccccccc}
\hline & \multicolumn{6}{c}{ Doses (\%) } \\
\cline { 2 - 6 } Cultivares & $\mathbf{0}$ & $\mathbf{2 5}$ & $\mathbf{5 0}$ & $\mathbf{1 0 0}$ & Médias & CV (\%) \\
\cline { 2 - 6 } & $21,67^{\text {NS }}$ & $\mathbf{2 2 , 6 9}$ & 22,75 & 22,84 & 22,49 & \multirow{2}{*}{9,46} \\
\hline Early Wonder & 21,99 & 22,38 & 21,73 & 19,14 & 21,31 & \\
Vermelha Comprida & 21,99 & &
\end{tabular}

NS: não significativo $(\mathrm{p}<0,05)$.

Para as variáveis: comprimento das raízes e de parte aérea de plântulas, houve efeito de doses para a cultivar Early Wonder (Figura 2); porém, para a cultivar Vermelha Comprida não houve efeito das doses no comprimento de parte aérea (Tabela 3), e o comprimento de raízes foi afetado, com tendência de estímulo ao 
crescimento com aumento das doses, sem contudo, observar-se um modelo adequado de ajuste de regressão.

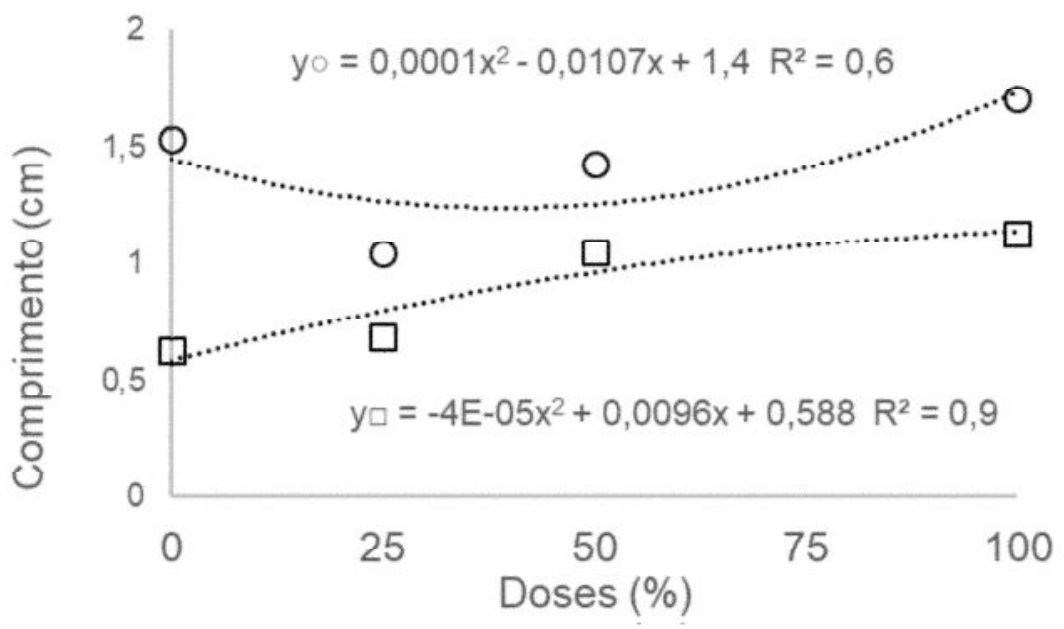

FIGURA 2. Comprimento de raízes ( ) e de parte aérea (O) de plântulas de beterraba, cultivar Early Wonder, sob diferentes doses de extrato de centeio.

TABELA 3. Valores médios de comprimento de raízes $(C R)$ e de parte aérea (CPA) de plântulas de beterraba, cultivar Vermelha Comprida, sob diferentes doses de extrato de centeio.

\begin{tabular}{ccc}
\hline \multirow{2}{*}{ Doses (\%) } & CR & CPA \\
\cline { 2 - 3 } & \multicolumn{2}{c}{ Cm } \\
\hline 0 & 0,80 & 0,46 \\
25 & 1,51 & 0,43 \\
50 & 0,91 & 0,45 \\
100 & 1,02 & 0,43 \\
\hline Médias & 0,94 & 0,44 \\
\hline CV (\%) & 22,3 & 33,2 \\
\hline
\end{tabular}

Desta forma pode-se perceber que doses acima de $25 \%$ causaram estímulo no crescimento de raízes de plântulas de ambas cultivares, e da parte aérea da cultivar Early Wonder. Carvalho et al. (2014) verificaram que extrato aquoso de aveia preta teve efeito benéfico sobre o crescimento da parte aérea de plântulas de alface, porém, negativo sobre o crescimento de raízes de plântula; os autores atribuem esse resultado a utilização pelas plântulas da reserva nutricional das sementes havendo a translocação desses componentes nutritivos para o hipocótilo.

Em relação à massa seca de raízes, observaram-se diferenças entre cultivares e doses (Figura 3A); para a cultivar Early Wonder a partir de $25 \%$ de concentração do extrato, há decréscimo na variável estudada; já para a cultivar Vermelha Comprida, a resposta foi contrária, e a partir da dose de $25 \%$, houve maior AGRARIAN ACADEMY, Centro Científico Conhecer - Goiânia, v.5, n.9; p. 2002018 
acúmulo de massa nas raízes. Carvalho et al. (2014) verificaram que extrato aquoso de aveia preta teve um efeito benéfico em relação a variável massa seca das raízes e massa seca da parte aérea de plântulas de alface.

A

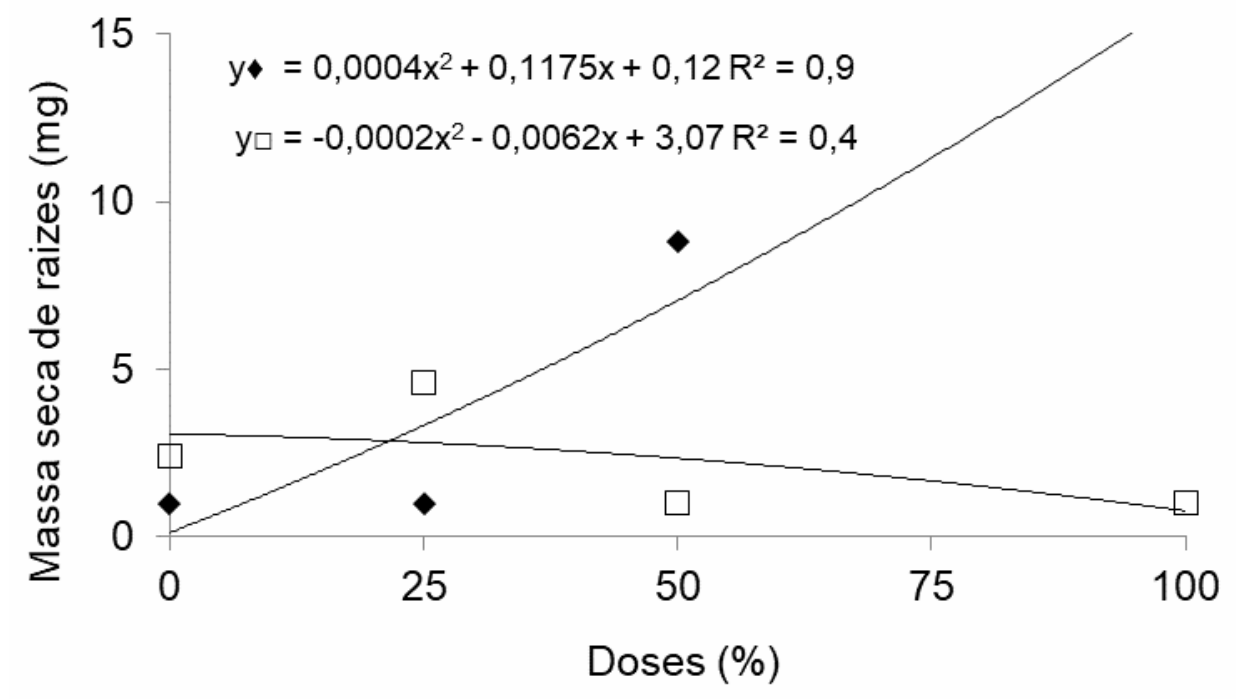

B

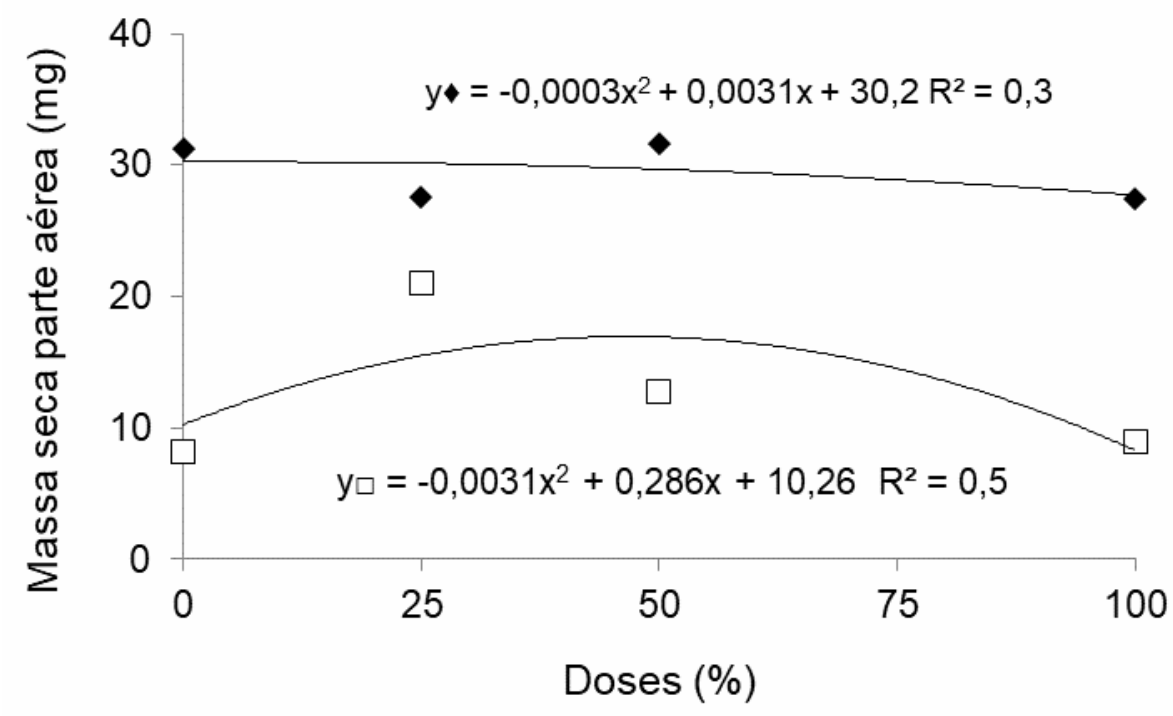

FIGURA 3. Valores médios da massa seca de raízes $(A)$ e de parte aérea $(B)$ de plântulas de beterraba, cultivares Vermelha Comprida ( $\downarrow$ ) e Early Wonder ( ), sob efeito de diferentes doses do extrato de centeio.

Em relação a massa seca de parte aérea de plântulas observaram-se diferenças entre as concentrações de extrato e as cultivares (Figura 3B), com destaque para maior acúmulo de massa de plântulas de beterraba da cultivar Early Wonder, na concentração de $25 \%$, sendo que doses maiores causaram redução nessa variável.

De forma geral, houve influência significativa do extrato de centeio sobre a germinação de sementes de beterraba, e conforme as doses do extrato aumentaram, a germinação das sementes reduziu; foi possível observar que o extrato de centeio proporcionou maior quantidade de plântulas anormais. O crescimento de plântulas de beterraba foi influenciado pelas concentrações de AGRARIAN ACADEMY, Centro Científico Conhecer - Goiânia, v.5, n.9; p. 2012018 
extrato de centeio, havendo também resposta diferencial em função da cultivar estudada.

\section{CONCLUSÃO}

O extrato de centeio reduz a germinação de sementes de beterraba. $O$ crescimento de plântulas de beterraba é afetado pelo extrato de centeio, com efeito variável em função da cultivar.

\section{REFERÊNCIAS}

ASLAM, F.; KHALIK, A.; MATLOOB, A.; TANVEER, A.; HUSSAIN, S.; ZAHIR, Z.A. Allelopathy in agro-ecosystems: a critical review of wheat allelopathy-concepts and implications. Chemoecology, v.27, p.1-24, 2017. Disponível em: <https://link.springer.com/article/10.1007/s00049-016-0225-x>.

BLANCO-CANQUI, H.; SHAVER, T.M.; LINDQUIST, J.L.; SHAPIRO, C.A.; ELMORE, R.W.; FRANCIS, C.A.; HERGERT, G.W. Cover Crops and Ecosystem Services: Insights from Studies in Temperate Soils. Agronomy Journal, v.6, p.2449-2474, 2015. Disponível em: <https://digitalcommons.unl.edu/agronomyfacpub/844/>

BASCHE, A.D., T.C KASPAR, S.V. ARCHONTOULIS, D.B. JAYNES, T.J. SAUER, T.B. PARKIN, AND F.E. MIGUEZ. Soil water improvements with the long-term use of a winter cover crop. Agricultural Water Management, v. 172, p.40-50, 2016. Disponível em: <https://doi.org/10.1016/j.agwat.2016.04.006>.

BRASIL. Ministério da Agricultura, Pecuária e Abastecimento. Regras para Análise de Sementes. Secretaria de Defesa Agropecuária. Brasília: MAPA/ACS 395p. 2009.

CARVALHO, W.P.; CARVALHO, G.J.; ABBADE NETO, D.O.; TEIXEIRA, L.G.V. Alelopatia de extratos de adubos verdes sobre a germinação e crescimento inicial de alface. Bioscience Journal, v. 30, n.3, p. 1-11, 2014. Disponível em: http://www.seer.ufu.br/index.php/biosciencejournal/article/view/13910.

CASTAGNARA, D.D.; MEINERZ, C.C.; MULLER, S.F.; SCHIMIDT, M.A.H.; PORTZ, T.M.; OBICI, L.V.; GUIMARÃES, V.F. Potencial alelopático de aveia, feijão guandu, azevém, e braquiária na germinação de sementes e atividade enzimática de pepino. Ensaios e Ciência- Ciências Agrárias, Biológicas e da Saúde, v.16, n.2, 31-42. 2012. Disponível em: http://pgsskroton.com.br/seer/index.php/ensaioeciencia/article/viewFile/2804/2658.

CHENG, F.; CHENG, Z. Research Progress on the use of Plant Allelopathy in Agriculture and the Physiological and Ecological Mechanisms of Allelopathy. Frontiers in Plant Science, v.6, art.1020, p. 1-16, 2015. Disponível em: https://www.ncbi.nlm.nih.gov/pmc/articles/PMC4647110/.

GUERRA, N.; SILVA, E.S.B.; TAVARES, A.M.; CARLET, A.; OLIVEIRA NETO, A.M.O. Interferência de plantas daninhas na cultura da beterraba em semeadura direta e transplantada. Revista Agro@mbiente On-line, v. 10, n. 3, p. 235-242, 2016. Disponível em: DOI: http://dx.doi.org/10.18227/1982-8470ragro.v10i3.3279. 
ISTA- International Rules for Seed Testing. Handbook on Seedling Evaluation Switzerland. 2013.

LARNEY, F.J.; NITSCHELM, J.J.; REGITNIG, P.J.; PEARSON, D.C.; BLACKSHAW, R.E.; LUPWAYI. Sugar beet response to rotation and conservation management in a 12-year irrigated study in southern Alberta. Canadian Journal of Plant Science, v.96, n.5, p. 776-789, 2016. Disponível em: <https://doi.org/10.1139/cjps-20160005>.

LATIF, S.; CHIAPUSIO, G.; WESTON, L.A. Chapter Two - Allelopathy and the Role of Allelochemicals in Plant Defence. Advances in Botanical Research, v.82, p.1954, 2017. Disponível em: <https://doi.org/10.1016/bs.abr.2016.12.001>.

MAGUIRE, J.D. Speed of germination aid in selection and evaluation for seeding emergence and vigor. Crop Science, v. 2, n. 2, p. 76-177, 1962. Disponível em: https://dl.sciencesocieties.org/publications/cs/abstracts/2/2/CS0020020176.

MOHAMMADI, G.R; NOROOZI, N; NOSRATTI, I. Germination and seedling growth of corn and some weed species in response to treatment with common vetch and rye extracts. Philippine Journal of Crop Ccience, v, 41, n.3 p. 83-87, 2016. Disponível em: https://www.cabi.org/gara/FullTextPDF/2017/20173034449.pdf .

MOORE, E.B.; WIEDENHOEFT, M.H.; KASPAR, T.C.; CAMBARDELLA, C.A. Rye cover crop effects on soil quality in no-till corn silage-soybean cropping systems. Soil Science Society of America Journal, v. 78, p.968-976, 2014.

NIEMEYER, H.N. Hydroxamic acids derived from 2-hydroxy2H-1,4-benzoxazin$3(4 \mathrm{H})$-one: fey defense chemicals of cereals. The Journal of Agricultural and Food Chemistry, vl. 57, n. 5, p. 1677-1695, 2009. Disponível em: $<$ https://pubs.acs.org/doi/abs/10.1021/jf8034034>.

VENTURELLI, S.; BELZ, R.G.; KAMPER, A.; BERGER, A.; HORN, K.; BOCKER, A.; et al.; Plants release precursors of histone deacetylase inhibitors to suppress growth of competitors. Plant Cell, v. 27, p. 3175-3189, 2015. Disponível em: $<$ www.plantcell.org/cgi/doi/10.1105/tpc.15.00585>.

VILANOVA, C.C.; COMIM, J.J.; MULLER JUNIOR, V.; URIARTE, J.F.; VENTURA, B.S.; SOUZA, M.; et al.,; Interferência de plantas de cobertura sobre a incidência de plantas invasoras e a produção de cebola sob sistema de plantio direto. Scientia Agraria, v.15, n.1, p.9-14, 2014. Disponível em: <http://dx.doi.org/10.5380/rsa.v15i1.41092>.

ZIECH, A.R.D.; CONCEIÇÃO, P.C.; LUCHESE, A.V.; BALIN, N.M.; CANDIOTTO, G.; GARMUS,T.G. Proteção do solo por plantas de cobertura de ciclo hibernal na região Sul do Brasil. Pesquisa Agropecuária Brasileira, v.50, n.5, p.374-382, 2015. Disponível em: < http://dx.doi.org/10.1590/S0100-204X2015000500004>. 